\title{
Volatile Organic Compounds (VOCs) Emitted by Ilex paraguariensis Plants are Affected by the Herbivory of the Lepidopteran Thelosia camina and the Coleopteran Hedypathes betulinus
}

\author{
Camila B. C. Martins, Diogo M. Vidal, Sandra M. S. Gomes and Paulo H. G. Zarbin* \\ Laboratório de Semioquímicos, Departamento de Química, Universidade Federal do Paraná, \\ CP 19081, 81531-990 Curitiba-PR, Brazil
}

\begin{abstract}
The profile of volatiles emitted by Ilex paraguariensis, leaves of which are used to produce a popular South American tea, were identified and compared among treatments. Headspace collections were performed for 24-72 hours for control, mechanical damage (MD), herbivory by larvae of Thelosia camina (TC), and by adults of Hedypathes betulinus (HB). Based on gas chromatography-mass spectrometry (GC-MS) and gas chromatography-Fourier transform infrared (GC-FTIR) analyses, 20 compounds were identified, totaling about 7, 5, 20, and $25 \mu \mathrm{g} /$ plant/treatment (control, MD, TC and HB, respectively). Statistical analyses revealed that control and MD treatments are different from TC and HB herbivory treatments. Furthermore, $\mathrm{HB}$ herbivory was distinctive from the other treatments at $24 \mathrm{~h}$ in that $\mathrm{HB}$ feeding induced a distinctive pattern of emission of terpenes. Major compounds per treatments were decanal for control and DM, 4,8-dimethylnona-1,3,7-triene (DMNT) and 2-undecanone for TC, and DMNT and $(E)$ - $\beta$-ocimene for HB.
\end{abstract}

Keywords: yerba mate tree, VOCs emission, DMNT, $(E)-\beta$-ocimene, 2-undecanone

\section{Introduction}

Leaves of the yerba mate tree, Ilex paraguariensis $\mathrm{St}$. Hil. (Aquifoliaceae), are dried and minced to produce one of the most popular teas of South America, known with different names (yerba mate, chimarrão or tereré) depending on the region of cultivation and techniques of preparation. ${ }^{1}$ Thus, the yerba mate tree is important for the economy and culture of South America. Ilex paraguariensis occurs naturally in Brazil, Argentina and Uruguay, with Thelosia camina (Schaus, 1920) (Lepidoptera, Eupterotidae) and Hedypathes betulinus (Klug, 1825) (Coleoptera, Cerambycidae) being its main pests. ${ }^{2}$

Volatile organic compounds (VOCs) are secondary metabolites of plants that play important defensive and attractive roles in the interactions between plants and other plants, herbivores, pathogens and pollinators, among other things. ${ }^{3,4}$ Plants emit VOCs from leaves, flowers and fruits into the atmosphere and from roots into the soil, ${ }^{5}$ and herbivory often induces the emission of novel VOC blends. ${ }^{4,6,7}$

Although the essential oil of I. paraguariensi ${ }^{3}$ and the volatiles emitted by yerba mate beverages have been studied

*e-mail: pzarbin@ufpr.br previously, ${ }^{8}$ the volatile profile from I. paraguariensis, or any other Ilex spp. (Aquifoliaceae), are unknown. Moreover, semiochemical studies of the yerba mate tree and its herbivores are scarce. Therefore, we undertook the present study of the VOCs emitted by I. paraguariensis before and after the herbivory by the lepidopteran, T. camina, and the coleopteran, H. betulinus.

\section{Experimental}

Plants and insects

Young yerba mate plants (100 days old), larvae of $T$. camina and adults of $H$. betulinus were collected in the field at a commercial farm of green yerba mate (I. paraguariensis) in São Mateus do Sul, Paraná, Brazil (25'52'27' S, 50²2'58' W) in October and November of 2015. Plants were maintained at room temperature, and insects were kept under controlled temperature, humidity and photoperiod $\left(25 \pm 2{ }^{\circ} \mathrm{C}\right.$; $70 \%$; L 12 h:D 12 h) until experiments began.

For the experiments, lepidopteran larvae were selected by size (approximately $4 \mathrm{~cm}$ long) and tested beetles were approximately the same size. As insects were collected in 
the field their exact age was unknown. Yerba mate plants contained three to four leaves and measured $15-20 \mathrm{~cm}$ in height.

\section{Volatile collections}

The collection of volatiles was performed using glass chambers $(11.5 \times 35 \mathrm{~cm})$ in a room with controlled temperature and photoperiod $\left(25 \pm 2{ }^{\circ} \mathrm{C} ; \mathrm{L} 12 \mathrm{~h}\right.$ :D $\left.12 \mathrm{~h}\right)$. Plants were watered every other day, and headspace samples were collected using a humidified and charcoal filtered airflow at approximately $0.75 \mathrm{~L} \mathrm{~min}^{-1}$ (per chamber). Volatiles were captured on glass columns containing 20 mg of HayeSep Q 80-100 mesh (Althech, Lokeren, Belgium). Desorption was performed with $300 \mu \mathrm{L}$ of double distilled HPLC-grade hexane, and an internal standard (IS) (heptadecane, $\mathrm{C}_{17}$ ) was added, resulting in a final concentration per extract of $5 \mathrm{ng} \mu \mathrm{L}^{-1}$. The known concentration of the IS was used to quantify all volatile compounds present in the extracts.

Plants were kept inside glass chambers for four days during all treatments: control, mechanical damage (MD) (two leaves were cut in half at the beginning of the experiment), herbivory by larvae of T. camina (TC) (two larvae fed on the plant inside the chamber), and by adults of $H$. betulinus (HC) (two beetles fed on the plant inside the chamber). To reduce the capture of volatiles from soil, plant roots were covered with aluminum foil.

Plant damage caused by herbivory was verified before the beginning of experiments to guarantee that at least one leaf would be left intact and one leaf had been injured. Insects were removed from the chambers after $24 \mathrm{~h}$, after which extracts were prepared every $24 \mathrm{~h}$ for three days, for a total of three extracts. Four repetitions of each treatment were performed.

\section{Analytical procedures and identification of volatiles}

Extracts were analyzed by gas chromatography-mass spectrometry (GC-MS) on a Shimadzu QP-2010 Plus equipped with a DB-5 column $(30 \mathrm{~m} \times 0.25 \mathrm{~mm}$ i.d., $0.25 \mu \mathrm{m}$ film thickness; Agilent Technologies, USA) and by gas chromatography-Fourier transform infrared spectroscopy (GC-FTIR) on a Shimadzu 2010 equipped with a DB-5 capillary column $(30 \mathrm{~m} \times 0.25 \mathrm{~mm}$ i.d., $0.25 \mu \mathrm{m}$ film thickness; Agilent Technologies, USA), coupled to a DiscovIR-GC (Spectra Analysis, USA) infrared detector $\left(4000-750 \mathrm{~cm}^{-1}\right.$, resolution $\left.4 \mathrm{~cm}^{1}\right)$.

Injections of $1 \mu \mathrm{L}$ were performed in the splitless mode, with an injector temperature of $250{ }^{\circ} \mathrm{C}$. The column oven temperature was held at $40^{\circ} \mathrm{C}$ for 1 minute, increased to $180^{\circ} \mathrm{C}$ at $5^{\circ} \mathrm{C} \mathrm{min}^{-1}$, then increased to $250^{\circ} \mathrm{C}$ at $10{ }^{\circ} \mathrm{C} \mathrm{min}^{-1}$, and held for 2 minutes. Helium was used as carrier gas at a column head pressure of $170 \mathrm{kPa}$. The same parameters were used for all GC-MS and GC-FTIR analyses.

Heptadecane was used as internal standard in a concentration of $5 \mathrm{ng} \mu \mathrm{L}^{-1}$ on each extract. Extract components with concentration lower than $1 \mathrm{ng} \mu \mathrm{L}^{-1}$ were not considered for the analyses due to their low concentrations, leading to difficulties on identification and quantification. Retention indices (RIs) were determined using commercial standards of $n$-alkanes $\left(\mathrm{C}_{10}\right.$ to $\left.\mathrm{C}_{26}\right)$. $\mathrm{RIs}$ and mass and infrared spectra were used to compare and identify VOCs already described in the literature. ${ }^{9,10}$ In adition to that, co-injections were performed with the following commercially available standards: nonane, decane, $\alpha$-pinene, limonene, linalool, eucalyptol, 2-phenylethanol, nonanal, decanal, ocimene, farnesene, 6-methyl-5-hepten-2-one, acetophenone, 2-undecanone (Sigma-Aldrich Chemical Company, Milwaukee, WI, USA).

\section{Statistical analyses}

Data was analyzed by principal components analysis (PCA), followed by a multivariate analysis of variance (MANOVA) using selected principal components as responsive variables, and a Tukey test. First, a full MANOVA model was tested with all possible interactions (volatiles, treatment and time). Then, all non significant effects were discarded and the best subset model was retained. All tests were performed using $\mathrm{R}$ studio version $0.99 .485 .{ }^{11}$

\section{Results}

Analysis of headspace collections of I. paraguariensis volatiles revealed 20 consistent peaks in chromatograms. In some cases, two to four compounds co-eluted as a single peak interfering with their identifications and quantifications. In total, 20 compounds were identified and six remained unidentified $(\mathrm{Uc})$. Identified compounds were classified as aliphatic and aromatic hydrocarbons, terpenes, aldehydes, alcohols, and ketones (Figures 1 and 2, Table 1).

All 20 compounds were detected in all treatments, but in varying concentrations according to treatment. (E)-- $\beta$-Ocimene (10) was the exception in that this compound was not detected in control plants (Table 1). Control and mechanically damaged plants (MD) emitted lower amounts of compounds when compared with herbivory treatments (TC and HB). Plants emitted total mean values ( 24 to $72 \mathrm{~h}$ ) of approximately 7.09, 5.45, 20.63, and $25.56 \mu \mathrm{g}$ in control, MD, $\mathrm{TC}$ and $\mathrm{HB}$, respectively. Major compounds varied according to time $(24-72 \mathrm{~h})$. If the whole period of the experiment 


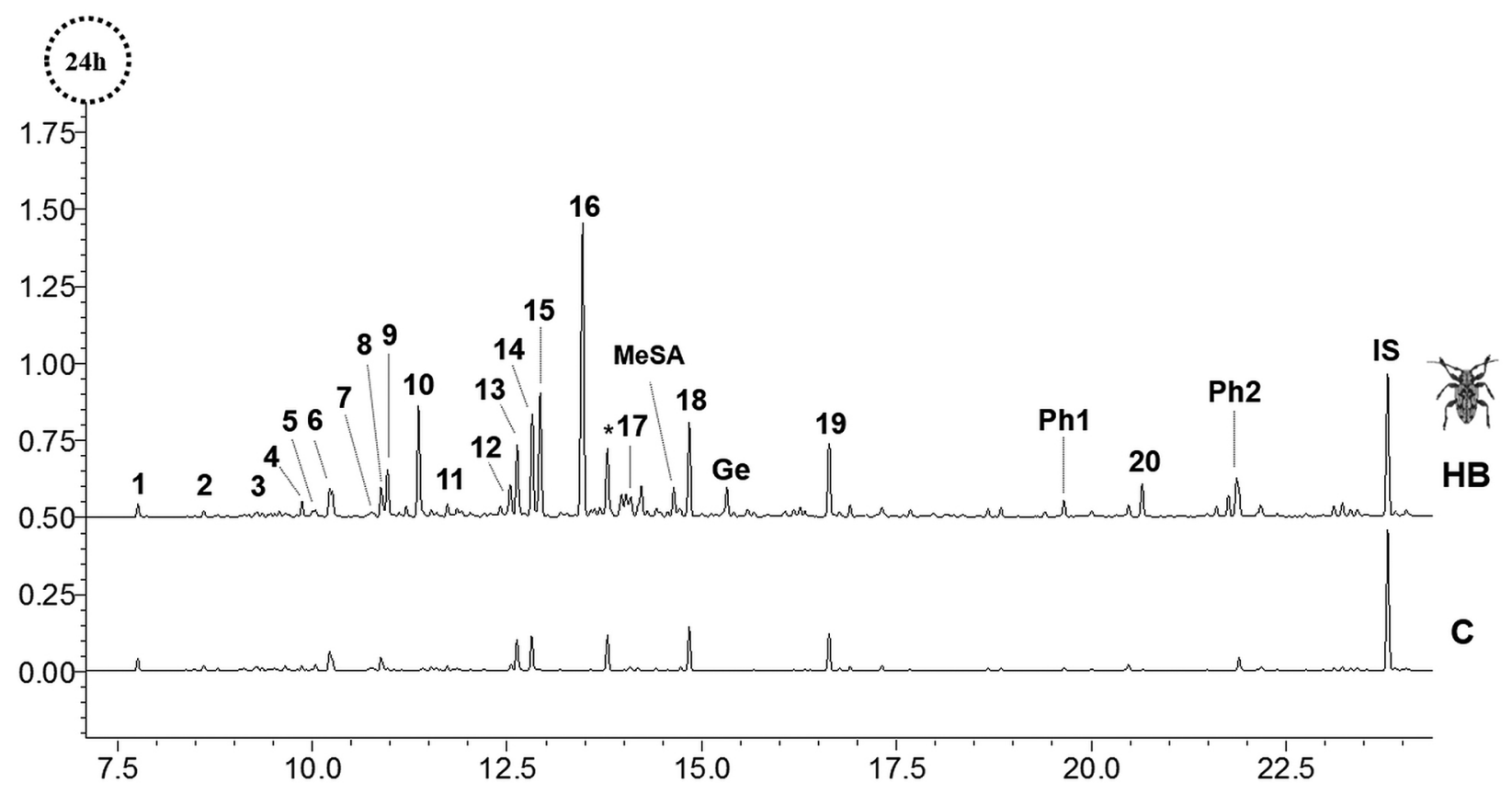

Figure 1. Comparisons of the chromatograms of Ilex paraguariensis extracts ( $24 \mathrm{~h}$ ) treated with the herbivory of Hedypathes betulinus (HB) and control plants (C). HB chromatogram represents the VOCs (1-20) emitted by yerba mate plants. MeSA: methyl salicylate; Ge: geraniol; components of $H$. betulinus pheromone, $\mathrm{Ph} 1$ and $\mathrm{Ph} 2:(E)$-6,10-dimethyl-5,9-undecadien-2-one (geranylacetone) and (E)-6,10-dimethyl-5,9-undecadien-2-yl acetate, respectively.

is considered per treatment, the major compounds were decanal (18) (total mean of $389.26 \pm 39.89 \mathrm{ng}$ in control, $333.80 \pm 64.19 \mathrm{ng}$ in MD) for control and MD treatments, and 2-undecanone (19) $(1032.39 \pm 198.47 \mathrm{ng}$ in TC and $953.28 \pm 88.21 \mathrm{ng}$ in $\mathrm{HB}$ ) for herbivory treatments. If only the peak of emission is considered per treatment, the major compounds were decanal (18) and 2-undecanone (19) (mean

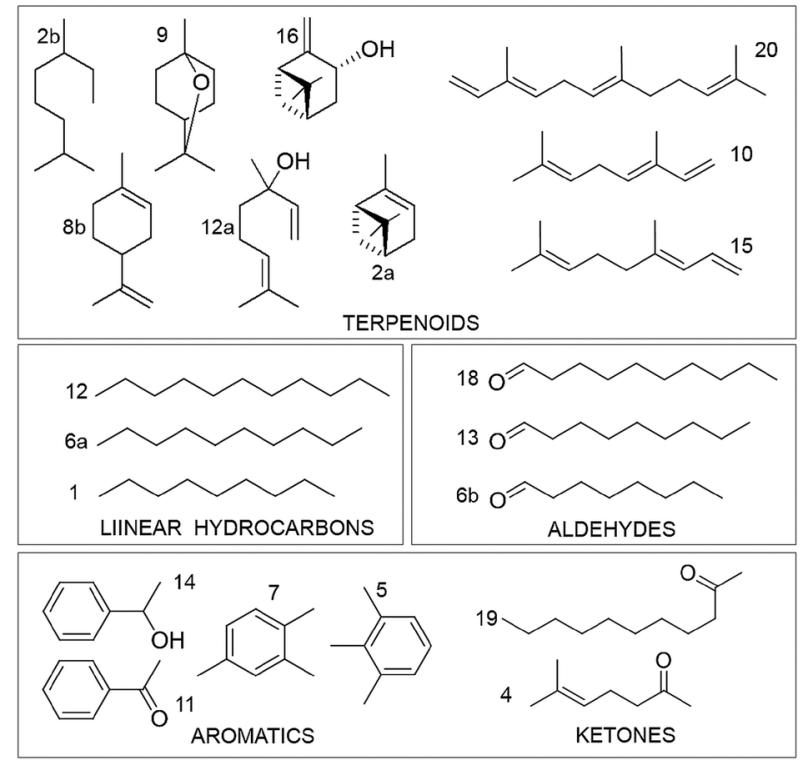

Figure 2. VOCs (1-20) emitted from Ilex paraguariensis plants treated with the herbivory by Thelosia camina (TC), Hedypathes betulinus (HB), mechanical damage (MD) and control. Compound names are in Table 1. of $377.62 \pm 80.18 \mathrm{ng}, 340.67 \pm 141.72 \mathrm{ng}$ at $24 \mathrm{~h})$ in the control; decanal (18) and 2-undecanone (19) (482.14 $\pm 121.41 \mathrm{ng}$ at $24 \mathrm{~h}, 332.40 \pm 97.32 \mathrm{ng}$ at $24 \mathrm{~h})$ in $\mathrm{MD}$; 2-undecanone (19) and 4,8-dimethylnona-1,3,7-triene (15) (DMNT) $(1420.08 \pm 460.78 \mathrm{ng}$ at $72 \mathrm{~h}$, and $1342.50 \pm 282.92 \mathrm{ng}$ at $24 \mathrm{~h})$ in TC; and $(E)-\beta$-ocimene (10) and DMNT (15) $(1555.81 \pm 562.66 \mathrm{ng}$ at $24 \mathrm{~h}, 1223.36 \pm 255.45 \mathrm{ng}$ at $24 \mathrm{~h})$ in HB.

HB extracts contained (E)-6,10-dimethyl5,9-undecadien-2-yl acetate (retention time (RT): 21.89 minutes, RI: 1583) and (E)-6,10-dimethyl5,9-undecadien-2-one (geranylacetone) (RT: 19.68 minutes, RI: 1455) (see Figure 1, Ph2 and Ph1, respectively), two of the three components of $H$. betulinus' pheromone. ${ }^{12}$ Geranylacetone was also present in control, MD and TC. Due to the impossibility to determine the concentration of geranylacetone emitted only by yerba mate plants in HB, this compound was removed from the analysis. Moreover, HB extracts contained the compounds methyl salicylate (MeSA) and geraniol (Ge) (Figure 1) in low concentrations, which were not considered for the quantification analyses.

DMNT (15) emitted by TC plants revealed a pattern of emission (Figure 3, pattern A) that was more common in this treatment when compared to DM and HB. In this pattern A, a high emission was observed in the first $24 \mathrm{~h}$, followed by a decrease at $48 \mathrm{~h}$ and by an even higher emission at $72 \mathrm{~h}$. Compounds 1-9, 11, 13 and 17-19 of TC treated plants $(\mathrm{n}=14)$ and $\mathbf{1 - 3}, \mathbf{5 - 8}$ and 19 of HB $(\mathrm{n}=8)$ followed this 
Table 1. Identification and quantification (mean $\pm \mathrm{SE}$ ) (ng) of VOCs released from Ilex paraguariensis treated plants (24-72 h): control; after mechanical damage; after herbivory by Thelosia camina; and after herbivory by Hedypathes betulinus

\begin{tabular}{|c|c|c|c|c|c|c|c|c|c|}
\hline \multirow{2}{*}{$\mathrm{N}$} & \multirow{2}{*}{ RI } & \multirow{2}{*}{ Chemical compound } & \multirow{2}{*}{ Control / ng } & \multicolumn{3}{|c|}{ Thelosia camina / ng } & \multicolumn{3}{|c|}{ Hedypathes betulinus / ng } \\
\hline & & & & $24 \mathrm{~h}$ & $48 \mathrm{~h}$ & $72 \mathrm{~h}$ & $24 \mathrm{~h}$ & $48 \mathrm{~h}$ & $72 \mathrm{~h}$ \\
\hline 1 & 892 & nonane $\mathrm{a}^{\mathrm{a}}$ & $108.6 \pm 43.9$ & $284.7 \pm 127.5$ & $197.2 \pm 73.2$ & $384 \pm 107.2$ & $231.2 \pm 36.1$ & $193.6 \pm 34.4$ & $243.3 \pm 45.1$ \\
\hline 2 & 927 & $\begin{array}{c}\alpha \text {-pinene }{ }^{\mathrm{a}}+ \\
\text { tetrahydrocitronellene } \\
\mathrm{b}\end{array}$ & $46.8 \pm 21.7$ & $131.3 \pm 59.1$ & $93 \pm 38$ & $256.8 \pm 97.6$ & $121 \pm 24.8$ & $92 \pm 18.3$ & $158.1 \pm 31.1$ \\
\hline 3 & 957 & $\mathrm{Uc}(\mathrm{a}+\mathrm{b})$ & $72.1 \pm 34.5$ & $212.3 \pm 98.4$ & $143.4 \pm 59$ & $273.7 \pm 84.2$ & $129.1 \pm 55.5$ & $105.3 \pm 48.7$ & $131.5 \pm 57$ \\
\hline 4 & 982 & 6-methyl-5-hepten-2-one ${ }^{\mathrm{a}, \mathrm{c}}$ & $52.6 \pm 19$ & $168.3 \pm 75.1$ & $95.6 \pm 36.0$ & $169.1 \pm 44.9$ & $334.6 \pm 70.6$ & $150.9 \pm 23.6$ & $193.3 \pm 22.4$ \\
\hline 5 & 991 & 1,2,3- trimethylbenzene $e^{\mathrm{b}}$ & $82.8 \pm 38.9$ & $199.2 \pm 97.8$ & $147.2 \pm 76.7$ & $417 \pm 150.9$ & $138.8 \pm 41.2$ & $73.2 \pm 47.5$ & $264.2 \pm 45.2$ \\
\hline 6 & 1001 & decane $^{\mathrm{a}}+$ octanal $^{\mathrm{b}}$ & $278.4 \pm 86$ & $563.4 \pm 213.1$ & $463.8 \pm 176.9$ & $819.7 \pm 247.9$ & $586.2 \pm 150.7$ & $489.2 \pm 125$ & $649.2 \pm 117.4$ \\
\hline 7 & 1024 & $\begin{array}{c}\mathrm{Uc}(\mathrm{c}, \mathrm{d}, \mathrm{e})+ \\
1,2,4 \text {-trimethylbenzene }\end{array}$ & $58.3 \pm 29$ & $138 \pm 80.6$ & $122 \pm 56.7$ & $344.6 \pm 138.2$ & $162.7 \pm 31.9$ & $127.4 \pm 34.8$ & $216.3 \pm 53.7$ \\
\hline 8 & 1029 & limonene $\mathrm{a}^{\mathrm{a}, \mathrm{c}}$ & $160.4 \pm 61.5$ & $340.5 \pm 121.6$ & $278.3 \pm 111.8$ & $555.3 \pm 202.4$ & $460.1 \pm 91.1$ & $345.4 \pm 88.3$ & $490.7 \pm 123.7$ \\
\hline 9 & 1034 & eucalyptol $^{\mathrm{a}}$ & $23.3 \pm 11.5$ & $87.5 \pm 26.7$ & $59.5 \pm 19.9$ & $134.2 \pm 56$ & $804.7 \pm 305.2$ & $149 \pm 45.4$ & $126.3 \pm 31.1$ \\
\hline 10 & 1050 & $(E)-\beta$-ocimene ${ }^{\mathrm{a}}$ & nd & $700.4 \pm 77.9$ & $39.6 \pm 13.8$ & $68.6 \pm 35.3$ & $1555.8 \pm 562.7$ & $262.4 \pm 160.9$ & $114.9 \pm 79.7$ \\
\hline 11 & 1066 & acetophenone $^{\mathrm{a}}$ & $51.8 \pm 29.7$ & $146.5 \pm 59.2$ & $114.6 \pm 58.5$ & $251.6 \pm 99.3$ & $201.3 \pm 44.4$ & $152.5 \pm 43.6$ & $175.4 \pm 32.4$ \\
\hline 12 & 1103 & linalool $^{\mathrm{a}}$ & $61.1 \pm 31$ & $1243.9 \pm 107.6$ & $194.5 \pm 63.8$ & $406.8 \pm 181.4$ & $990.9 \pm 487.4$ & $277.7 \pm 94.6$ & $339.3 \pm 100.6$ \\
\hline 13 & 1107 & nonanal $^{\mathrm{a}, \mathrm{c}}$ & $278.9 \pm 66$ & $518.8 \pm 151.8$ & $431.2 \pm 132.3$ & $568.6 \pm 116.8$ & $738.6 \pm 163.1$ & $647.4 \pm 88.2$ & $630.5 \pm 71.2$ \\
\hline 14 & 1116 & 2-phenylethanol ${ }^{\mathrm{a}}$ & $141.6 \pm 64.7$ & $555.3 \pm 286.9$ & $441.6 \pm 156.2$ & $399.4 \pm 32.8$ & $999.7 \pm 490.5$ & $836.6 \pm 367.9$ & $726.5 \pm 331.4$ \\
\hline 15 & 1120 & $\mathrm{DMNT}^{\mathrm{b}}$ & $21.6 \pm 13.3$ & $1342.4 \pm 282.9$ & $268.7 \pm 22.1$ & $165.4 \pm 64.3$ & $1223.3 \pm 255.5$ & $282.1 \pm 80.7$ & $208 \pm 88.3$ \\
\hline 16 & 1142 & $(E)$-pinocarveol ${ }^{\mathrm{b}}$ & nd & $56.8 \pm 23.3$ & $116.4 \pm 82.2$ & $11.8 \pm 7$ & $1035.3 \pm 838.9$ & $603.3 \pm 447.3$ & $455.6 \pm 225.5$ \\
\hline 17 & 1170 & Uc $\mathrm{f}$ & $73 \pm 27.1$ & $141.3 \pm 43.6$ & $109.9 \pm 65.7$ & $217.4 \pm 107.8$ & $189 \pm 40.2$ & $171.1 \pm 17.2$ & $142.6 \pm 58.4$ \\
\hline 18 & 1206 & decanal $^{\mathrm{a}, \mathrm{c}}$ & $377.6 \pm 80.1$ & $616.1 \pm 169.4$ & $500 \pm 140.2$ & $652.1 \pm 122$ & $784.8 \pm 177.6$ & $649.1 \pm 114.6$ & $648.2 \pm 72.4$ \\
\hline 19 & 1297 & 2-undecanone & $340.6 \pm 141.7$ & $882.8 \pm 274.6$ & $794.2 \pm 262.9$ & $1420 \pm 460.8$ & $897.7 \pm 205$ & $929.9 \pm 159.1$ & $1032.1 \pm 171$ \\
\hline 20 & 1513 & $\alpha$-farnesene $\mathrm{e}^{\mathrm{a}}$ & $4.6 \pm 3.8$ & $133.3 \pm 49.5$ & $26.5 \pm 9.4$ & $9.4 \pm 5.5$ & $361.3 \pm 153.1$ & $85.7 \pm 14.1$ & $43.5 \pm 8.9$ \\
\hline
\end{tabular}

N: peak number; RI: retention indices; SE: standard error; Uc: unidentified compound; nd: not detected. aIdentification based on co-injections with authentic

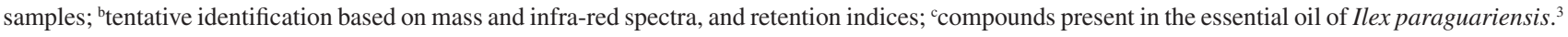
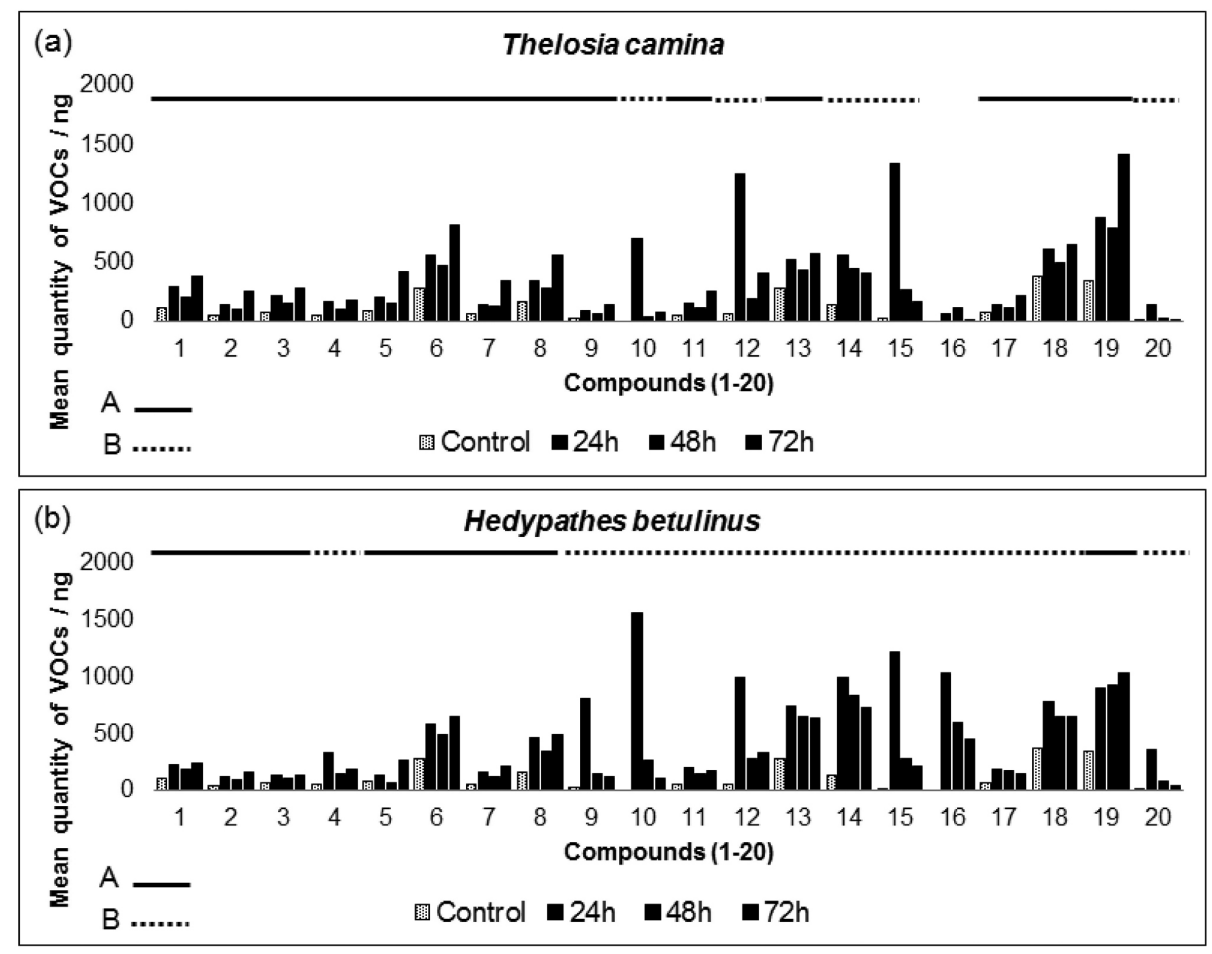

Figure 3. Graphical representation of the two different patterns of emissions (A: solid line and B: dotted line) of the VOCs (1-20) from Ilex paraguariensis control plants and herbivory treated plants: (a) Thelosia camina; (b) Hedytpathes betulinus, according to time (24-72 h). In pattern A: peak of emission at $72 \mathrm{~h}$ or up regulated; in pattern B: peak of emission at $24 \mathrm{~h}$ or down regulated. 
pattern. In a second pattern (Figure 3, pattern B), VOCs peaked in the first $24 \mathrm{~h}$ of experiment, and then decreased gradually. Pattern B was detected for the compounds 4 , 9-18 and 20 of HB treated plants $(\mathrm{n}=12)$ and 10, 12, 14, 15 and 20 of TC plants $(n=5)$ (Table 1$)$.

Statistical results indicated that the first two principal components of the PCA explained $80.08 \%$ of the variation of the VOCs emitted by I. paraguariensis. MANOVA revealed that volatiles did not interact with treatment and time (Pillai trace $=0.46, \mathrm{~F} 6,12=0.06, \mathrm{P} \geq 0.1$ ) but there were significant interactions between volatiles and treatments (Pillai trace $=0.65$, F 3, $6=7.49 \mathrm{e}-06$, $\mathrm{P} \geq 0.001^{*}$ ) and between volatiles and time (Pillai trace $=0.32, \mathrm{~F} 2,4=0.004, \mathrm{P} \geq 0.01 *)$, indicating specificities in both correlations. PC1 represented the variation of concentration of volatiles per treatment ( $\mathrm{PC} 1$ : volatiles and treatments: $\mathrm{P} \geq 0.001^{*}$; volatiles and time: $\mathrm{P} \geq 0.1^{*}$ ) and $\mathrm{PC} 2$ represented the variation of concentration of volatiles (dynamic of emission) along the experimental time (24-72 h) (PC2: volatiles and treatments: $\mathrm{P} \geq 0.5^{*}$; volatiles and time: $\mathrm{P} \geq 0.01 *$ ) (see Figure 4 ).

Tukey tests with PC1 $(60.70 \%)$ showed that control and MD plants are different from TC and HB plants, and that there were no differences between treatments and time

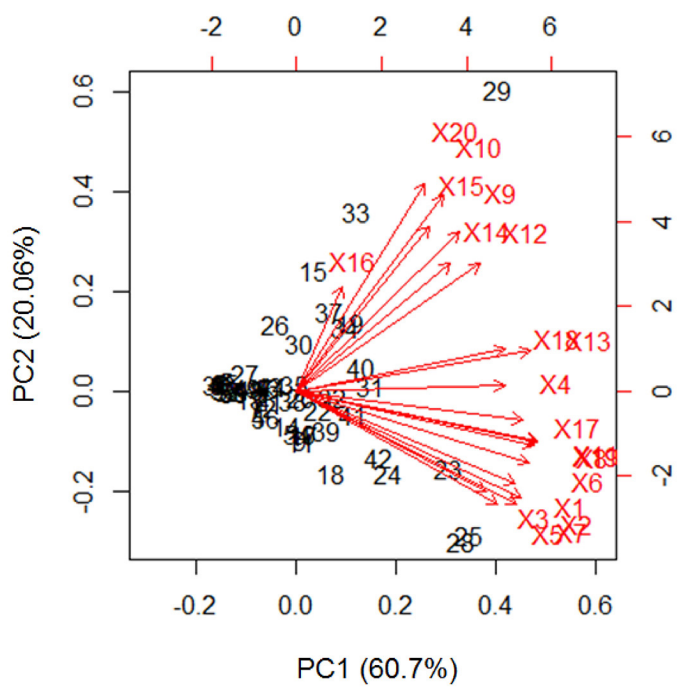

Figure 4. PCA plot representing VOCs 1-20 (X1 - X20) distributed on $\mathrm{PC} 1$ and PC2. VOCs emitted from Ilex paraguariensis plants treated with the herbivory by Thelosia camina (TC), Hedypathes betulinus (HB), mechanical damage (MD) and control.

(Figure 5a). Tukey tests with PC2 (20.06\%) revealed that HB plants are different than control and TC plants, but are not different from MD plants, and that $24 \mathrm{~h}$ was different from $72 \mathrm{~h}$, although $24 \mathrm{~h}$ and $72 \mathrm{~h}$ were the same as $48 \mathrm{~h}$ (Figure 5b).
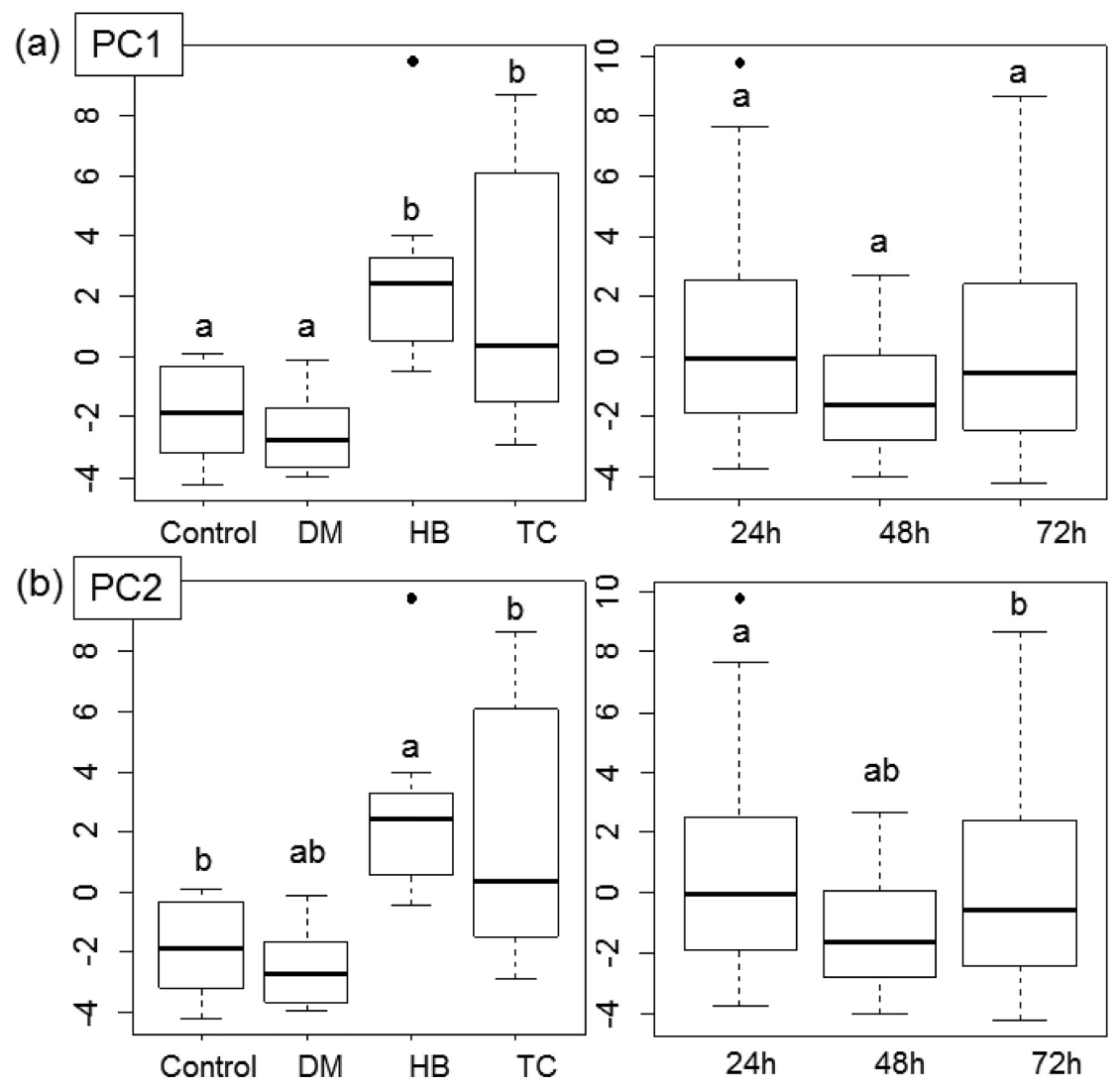

Figure 5. PCs 1 (a) and 2 (b): comparisons of treatments (control, mechanical damage (MD), and herbivories by Hedytpathes betulinus (HB) and Thelosia camina (TC)) and times (24, 48, and $72 \mathrm{~h}$ ). Different letters indicate significant differences. 


\section{Discussion}

Volatile organic compounds are secondary metabolites of plants, usually lipophilic liquids with low molecular weight and high vapor pressure at ambient temperatures, and they are divided into several classes based on their biosynthetic origin; primarily, terpenoids, phenylpropanoids/benzenoids, fatty acid derivatives, and amino acid derivatives. ${ }^{13}$ In the current study, VOCs emitted by I. paraguariensis plants were composed mainly by terpenoids $(n=7)$ (Figure 2). Terpenoids constitute the largest class of plant volatiles represented mainly by isoprene $\left(\mathrm{C}_{5}\right)$, monoterpenes $\left(\mathrm{C}_{10}\right)$, and sesquiterpenes $\left(\mathrm{C}_{15}\right)$. Moreover, terpenoids are of crucial importance in chemical ecology of pollinator attraction, plant defense, and interaction with the surrounding environment. ${ }^{14}$

All terpenoids are synthesized from two $\mathrm{C}_{5}$ precursors, isopentenyl diphosphate (IPP) and dimethylallyl diphosphate (DMAPP) at the MEP (methylerythritol 4-phosphate), which occurs at the cytoplasm of plant cells and MEV (mevalonate) pathways, ${ }^{14}$ which occurs inside plastids, as the chloroplast. These biosynthetic pathways of terpenoid compounds may be the most important for the response against mechanical damage and herbivory injuries for T. camina and H. betulinus. Furthermore, terpenoids are also produced by control yerba mate plants indicating that the biosynthesis is also active if plants are not injured. However, there were clear differences in quantity and proportion of volatiles altering the bouquet of VOCs according to treatment. This indicates that, although apparently the same biosynthetic pathways might be active in the plant with or without injury, there must be significant change involving pathways and/or terpene synthase enzymes specifically activated after herbivory.

Herbivory treatments induced yerba mate plants to emit higher amounts of VOCs (Table 1), especially the homoterpene (E)-4,8-dimethyl-1,3,7-nonatriene (DMNT) $(\mathbf{1 5})$ and the monoterpene $(E)$ - $\beta$-ocimene (10) (the latter was not emitted by control plants) in TC treatments, and 2-undecanone (19) and DMNT (15) (homoterpene) in HB treatments. $(E)$ - $\beta$-Ocimene (10) could function in yerba mate plants specifically for defense against herbivorous insects and microorganisms. This compound, present in the essential oil of Lavandula multifida (Lamiaceae), inhibited the filamentation of the fungus Candida albicans (Berkhout, 1923) (Saccharomycetaceae). ${ }^{15}$ Moreover, (E)- $\beta$-ocimene produced by transgenic plants (lima bean and corn) induced priming responses of other plants, successfully attracting predators and parasitoids. ${ }^{16}$ In addition, $\beta$-ocimene induced the increase of methyl jasmonate and transcript levels of defense/stress-inducible genes in tissue levels in Arabidopsis thaliana DMNT (15) was produced in high amounts by yerba mate plants after both treatments of herbivory (TC and HB). DMNT and 4,8,12-trimethyltrideca-1,3,7,11-tetraene (TMTT) are degradation products of the terpenoids nerolidol and geranlyl-linalool. ${ }^{18}$ They can be synthesized by many angiosperms and were detected in the headspace of many plant species after herbivory. ${ }^{19,20}$ DMNT transgenically produced by lima bean plants (Phaseolus lunatus, Fabaceae) is attractive to the predatory mite, Phytoseiulus persimilis (Athias-Henriot, 1957) (Acarina, Phytoseiidae). ${ }^{20}$ Moreover, DMNT is one of the main constituents of the mixture of VOCs emitted by herbivore-attacked maize plants (Zea mays, Poaceae) that attracts herbivore enemies. ${ }^{21}$

2-Undecanone (19) is a constituent of Solanaceae and other plant families, and it has been shown to have toxic and/or repellent properties against some insects species. ${ }^{22}$ In tomato plants (Lycopersicon hirsutum f. glabratum, Solanaceae), the 2-undecanone found in the glandular trichome of leaves negatively affects the growth and survival of Helicoverpa zea (Boddie, 1850) (Lepidoptera, Noctuidae) and Manduca sexta (Linnaeus, 1758) (Lepidoptera, Sphingidae). ${ }^{23}$ However, this ketone provided a short-range chemical cue that provoked the walking, but not flying activity, of the tomato potato psyllid, Bactericera cockerelli (Sulc, 1909) (Hemiptera, Triozidae). ${ }^{22}$ Moreover, 2-undecanone was attractive in a short-range distance to the olive bark beetle, Phloeotribus scarabaeoides (Bernard, 1788) (Coleoptera, Curculionidae). ${ }^{24}$

The aldehyde decanal (18), the major compound emitted by undamaged (control) yerba mate and mechanically damaged plants, has been observed as a component of the bouquet of volatiles of various plant species, before and after herbivory damage. For example, it is emitted by red clover plants (Trifolium pretense, Fabaceae) after the attack of Spodoptera littoralis (Lepidoptera, Noctuidae), exibiting a positive correlation between herbivory damage and emission. ${ }^{25}$

Therefore, all major compounds $(\mathbf{1 0}, \mathbf{1 5}, 18$ and 19) emitted by yerba mate plants after the herbivory of T. camina and H. betulinus have been reported as both repellents to herbivores or microorganisms, and attractants to the natural enemies of herbivores. Hence, they should be tested as repellents against I. paraguariensis herbivores, and as attractants of natural enemies of these herbivores to corroborate this hypothesis.

HB extracts contained two of the three components of $H$. betulinus pheromone. The major compound produced and emitted by males is $(E)$-6,10-dimethyl-5,9-undecadien2 -yl acetate and one of the two minor compounds is 
geranylacetone $((E)$-6,10-dimethyl-5,9-undecadien2-one). ${ }^{12}$ Geranylacetone is a component of the bouquet emitted by yerba mate plants and has been indicated as a precursor of the major component of $H$. betulinus pheromone. ${ }^{26}$

Methyl salicylate (MeSA) and geraniol were found in HB extracts, and are well known as components of the herbivore induced plant volatile (HIPV) bouquet of many plant species. MeSA is an important signaling compound of systemic acquired resistance (SAR) in plants, ${ }^{27}$ and is involved in the response against herbivory in different plant cultures. ${ }^{7,28}$ For example, it attracted different families of beneficial insects in open field and hop yards (e.g. Syrphidae, Braconidae, Empididae, Sarcophagidae), ${ }^{28,29}$ and affected the abundance of organisms of different trophic levels in studies with Brassica rapa (Brassicaceae). ${ }^{30}$ Furthermore, geraniol is a known HIPV and it attracted wasps and flies in the families Braconidae (Hymenoptera) and Sarcophagidae (Diptera) in open field and hop yards experiments, ${ }^{29}$ indicating its role in defense.

Leaves usually release small quantities of volatiles, but after herbivory, many more volatiles are released, attracting both parasitic and predatory insects (natural enemies specific to the herbivores), and also inducing defense responses in neighboring plants. ${ }^{31}$ The unique bouquet emitted by yerba mate plants after the herbivory of both T. camina and $H$. betulinus reflects this dramatic increase in the volatiles emitted, but not in their composition. The absence of qualitative differences against MD and herbivory treatments was in a certain way expected as phytophagous insects that cause extensive feeding damage on plant tissues induce changes in gene expression and accumulation of secondary metabolites similar to mechanical wounding. ${ }^{32}$ However, elicitors are usually present in the oral secretion of lepidopteran larvae inducing defense responses in plants ${ }^{7}$ and might be responsible for the quantitative differences between HB and MD treated plants. This quantitative distinction is likely to affect the perception of enemies of these herbivores, as it is also suggested by the two different patterns of emission in both herbivories (A in TC and B in HB, Figure 3).

When the essential oil of yerba mate plants extracted by hydrodistillation was analyzed by GC-MS, 32 compounds were identified. ${ }^{3}$ In this study, only four of these compounds were detected in the VOCs emitted by I. paraguariensis control and treated plants (see Table 1). Such difference in composition could be due to different location of production, or the VOCs emitted by plants being rapidly eliminated by stomata or through cuticle, whereas the volatiles obtained in essential oil extractions are stored inside the leaves.
A related research study investigated the volatiles emitted by the infusion of green yerba mate and roasted yerba mate leaves. The main compounds were tentatively identified in green yerba mate as linalool, $\alpha$-terpineol, and trans-linalool oxide, and in roasted yerba mate as $(E, Z)-2,4$-heptadienal isomers and 5-methylfurfural. ${ }^{8}$ Except for linalool, none of these compounds were identified in the VOCs emitted by yerba mate plants. Moreover, studies of the yerba mate tea composition revealed that the major compounds are phenolic compounds, being the isomers caffeoylquinic and dicaffeoylquinic acids the major components detected in the phenolic fraction. Besides that, mixed mono-, di- and tri-esters of quinic acid and other hydroxycinnamates, and several quercetin and kaempferol glycosides were also identified. $^{33}$

\section{Conclusions}

Yerba mate plants emitted the same VOCs before and after being mechanically and herbivory damaged by its main pests, Thelosia camina and H. betulinus. The only exception was $(E)$ - $\beta$-ocimene $(\mathbf{1 0})$, the only unique compound from damaged plants. Herbivory had a total mean emission (in ng) for 24 to $72 \mathrm{~h}$ of approximately two and three times more when compared with control, and three and four times more if compared with MD. Moreover, the major compounds of herbivory presented the homoterpene DMNT (15) in common, along with $(E)-\beta$-ocimene $(\mathbf{1 0})$ in TC and 2-undecanone (19) in HB. Control and MD shared the same major compounds, decanal (18) and 2-undecanone (19). All major compounds have been cited in the literature to act in plant defense as repellents (herbivores) or attractants (natural enemies of herbivores) of insets, depending on the insect feeding habit, and bioassays have to be performed to support this hypothesis.

The ecological and evolutionary roles of secondary metabolites have been associated with allelopathic interactions among plants, defense against animals, protection from harmful insects, resistance to microbial attacks, healing of plant organ wounds, water regulation, and attraction of insects and animals for pollination. ${ }^{15,34}$ Identifying the VOCs emitted by plants of I.paraguariensis is the first step before studying and understanding the ecological roles of these compounds in tritrophic interactions among this plant and its herbivores and natural enemies.

\section{Acknowledgments}

The authors thank Dr Jeffrey Aldrich for revising the manuscript, the commercial farm Vier in São Mateus do 
Sul-PR for the yerba mate trees and insects, Rafael G. Moreira for the programming in Excel, Dr Maurício Osvaldo Moura and Dr Melise C. Lecheta for helping with the statistical analyses, the Conselho Nacional de Desenvolvimento Científico e Tecnológico (CNPq), the Fundação Araucária and the Coordenação de Aperfeiçoamento de Pessoal de Nível Superior (CAPES) and the INCT - Semioquímicos na Agricultura for the financial support.

\section{References}

1. Bracesco, N.; Sanchez, A.; Contreras, V.; Menini, T.; Gugliucci, A.; J. Ethnopharmacol. 2011, 136, 378.

2. Borges, L. R.; Lázzari, S. M. N.; Lázzari, F. A.; Rev. Bras. Entomol. 2003, 47, 563.

3. Bastos, B. P. C.; Figueiredo, M. B.; Almeida, E.; O Biológico 2006, 28, 189.

4. Martins, C. B.; Zarbin, P. H.; J. Chem. Ecol. 2013, 39, 602.

5. Maffei, M.; S. Afr. J. Bot. 2010, 76, 612.

6. Turlings, T. C.; Tumlinson, J. H.; Lewis, W. J.; Science 1990, 250, 1251.

7. Pinto-Zevallos, D. M.; Martins, C.; Pellegrino, A. C.; Zarbin, P. H.; Quim. Nova 2013, 36, 1395.

8. Machado, C. C. B.; Bastos, D. H. M.; Janzantti, N. S.; Facanali, R.; Marques, M. O. M.; Franco, M. R. B.; Quim. Nova 2007, $30,513$.

9. http://www.pherobase.com/kovats/, accessed in October 2016.

10. Adams, R. P.; Identification of Essential Oil Components by Gas Chromatography/Mass Spectrometry, $4^{\text {th }}$ ed.; Allured Publishing Corporation: Illinois, USA, 2007.

11. R Studio Team; RStudio: Integrated Development for $R$ Version 0.99.485, RStudio, Inc., Boston, MA, USA, 2009-2015.

12. Fonseca, M. G.; Vidal, D. M.; Zarbin, P. H.; J. Chem. Ecol. 2010, 36, 1132.

13. Dudareva, N.; Klempien, A.; Muhlemann, J. K.; Kaplan, I.; New Phytol. 2013, 198, 16.

14. Nagegowda, D. A.; FEBS Lett. 2010, 584, 2965.

15. Zuzarte, M.; Vale-Silva, L.; Gonçalves, M.; Cavaleiro, C.; Vaz, S.; Canhoto, J.; Pinto, E.; Salgueiro, L.; Eur. J. Clin. Microbiol. Infect. Dis. 2012, 31, 1359.
16. Muroi, A.; Ramadan, A.; Nishihara, M.; Yamamoto, M.; Ozawa, R.; Takabayashi, J.; Arimura, G.-I.; PLoS One 2011, 6, e24594.

17. Godard, K.-A.; White, R.; Bohlmann, J.; Phytochemistry 2008, 69, 1838.

18. Koch, T.; Krumm, T.; Jung, V.; Engelberth, J.; Boland, W.; Plant Physiol. 1999, 121, 153.

19. Boland, W.; Feng, Z.; Donath, J.; Gäbler, A.; Naturwissenschaften 1992, 79, 368.

20. Kappers, I. F.; Aharoni, A.; Van Herpen, T. W.; Luckerhoff, L. L.; Dicke, M.; Bouwmeester, H. J.; Science 2005, 309, 2070.

21. Degenhardt, J.; Gershenzon, J.; Planta 2000, 210, 815.

22. Davidson, M.; Butler, R.; Taylor, N.; Nielsen, M.; Sansom, C.; Perry, N.; Zydenbos, S.; New Z. Plant Prot. 2014, 67, 184.

23. Farrar, R. R.; Kennedy, G. G.; Entomol. Exp. Appl. 1987, 43, 17.

24. Szuman-Szumski, K.; Pe, A.; Kelly, D.; Campos, M.; BioControl 1998, 43, 345.

25. Kigathi, R. N.; Unsicker, S. B.; Reichelt, M.; Kesselmeier, J.; Gershenzon, J.; Weisser, W. W.; J. Chem. Ecol. 2009, 35, 1335.

26. Zarbin, P. H.; Fonseca, M. G.; Szczerbowski, D.; Oliveira, A. R.; J. Chem. Ecol. 2013, 39, 358.

27. Park, S.-W.; Kaimoyo, E.; Kumar, D.; Mosher, S.; Klessig, D. F.; Science 2007, 318, 113.

28. James, D. G.; Price, T. S.; J. Chem. Ecol. 2004, 30, 1613.

29. James, D. G.; J. Chem. Ecol. 2005, 31, 481.

30. Orre, G.; Wratten, S.; Jonsson, M.; Hale, R.; Biol. Control. 2010, 53, 62 .

31. Paré, P. W.; Tumlinson, J. H.; Plant Physiol. 1999, 121, 325.

32. Walling, L. L.; J. Plant Growth Regul. 2000, 19, 195.

33. Bravo, L.; Goya, L.; Lecumberri, E.; Food. Res. Int. 2007, 40, 393.

34. Svoboda, K. P.; Svoboda, T. G.; Syred, A.; Syred, P.; Secretory Structures of Aromatic and Medicinal Plants: a Review and Atlas of Micrographs, $1^{\text {st }}$ ed.; Microscopix Publications: Beguildi, Knighton, United Kingdom, 2000.

Submitted: June 9, 2016

Published online: October 18, 2016 